\title{
AVALIAÇÃO DE ILUMINAÇÃO EM UMA MARCENARIA
}

\author{
EVALUATION OF LIGHTING IN WOODWORK
}

\author{
Danyelle Bianca Xavier Donati ${ }^{1}$, Esp. \\ Fabiano Takeda ${ }^{2}$, M.Sc.
}

\author{
(1) Universidade Alto Vale do Rio do Peixe \\ e-mail: danybianca@hotmail.com \\ (2) Universidade Federal de Santa Catarina \\ e-mail: takeda.f@bol.com.br
}

Palavras-chave: iluminação, marcenaria, iluminância.

\begin{abstract}
O artigo busca verificar as condições da iluminação artificial em ambientes construídos, no caso em indústrias de móveis de pequeno porte, marcenarias, e como esta afeta o trabalho realizado nestes ambientes. Tomando a cidade de Fraiburgo - SC como recorte espacial, uma pesquisa foi realizada para avaliar as condições do objeto de estudo através de levantamento físico e sua correlação com os padrões ideais existentes na literatura e na legislação de referência. Os dados coletados e analisados de modo quantitativo e qualitativo tiveram como finalidade gerar resultados para além de fazer a conferencia das condições atuais, também poderem trazer sugestões e diretrizes para adequações do ambiente em questão. A análise revelou que mesmo os resultados das médias das medições estando de acordo com os índices presentes nas normas vigentes, outros elementos, como a iluminação natural, revestimentos, tipo de luminárias e layout, devem ser levados em consideração para que o ambiente apresente um verdadeiro conforto ambiental e ergonômico.
\end{abstract}

\section{Keywords: lighting, woodwork, illuminance.}

The article tries to verify the artificial lighting conditions in built environments, in the case of small furniture industries, woodwork, and how it affects the work done in these places. Taking the city of Fraiburgo - SC as a space cut, a survey was done to evaluate the conditions of the object of study through physical survey and its correlation with the ideal standards existing in the literature and reference legislation. The data collected and analyzed in a quantitative and qualitative way had the purpose of generating results in addition to conferring the current conditions, and could also provide suggestions and guidelines for adaptations of the environment in question. The analysis revealed that even the results of the averages of the measurements being in agreement with the indices present in the current norms, other elements, such as the natural lighting, coatings, type of luminaires and layout, must be taken into account for the environment to present a true environmental and ergonomic comfort.

Realização:
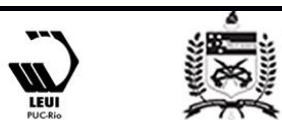


\section{$16^{\circ}$ \\ ERGODESIGN USIHC CINAHPA}

\section{Introdução}

A luz sempre esteve presente na vida do homem, desde sua concepção mais básica envolvendo o passar do dia, onde apenas a luz do Sol ministrava quando as pessoas estariam exercendo suas atividades laborais ou quando estariam na segurança de seus abrigos para se proteger de intempéries e animais, norteando assim a vida social e produtiva. Também estão envolvidos neste assunto os aspectos físicos e fisiológicos, do corriqueiro ato de enxergar, que em conjunto aos aspectos psicológicos do homem influem diretamente nas questões de percepção do meio em que se está inserido, fato corroborado por Pereira e Souza (2000, p.42) ao dizerem que "a evolução da humanidade tem sido feita predominantemente à luz do dia e do sol, o que não surpreende pelo fato de que o máximo de sensitividade do olho humano ocorre na faixa do espectro solar".

A utilização da iluminação de modo inadequado, ou até mesmo a falta desta, também apresenta um impacto importante na vivência das pessoas e trabalhadores, isto é evidenciado por Pereira e Souza (2000, p.05) ao citarem que uma iluminação inadequada pode causar desconforto e fadiga visual, dor de cabeça, ofuscamento, redução da eficiência visual ou mesmo acidentes, sendo que uma boa iluminação aumenta a produtividade, gera um ambiente mais prazeroso e pode também salvar vidas. Portanto, garantir uma iluminação adequada é uma das principais responsabilidades não só dos projetistas, mas também de administradores e autoridades locais.

Gestores vêm buscando melhorias no ambiente de trabalho, com foco na obtenção de maior produtividade, e junto a isso a conscientização para a melhoria das condições de trabalho de seus colaboradores, no intuito de garantir-lhes segurança e conforto ambiental, através de processos administrativos, de higiene ocupacional e da ergonomia.

Embora já se veja a implantação da Engenharia de Segurança do Trabalho em conjunto com a Engenharia de Produção em muitos setores $16^{\circ}$ Ergodesign - Congresso Internacional de Ergonomia e Usabilidade de Interfaces Humano Tecnológica: Produto, Informações Ambientes Construídos e Transporte

$16^{\circ}$ USIHC - Congresso Internacional de Ergonomia e Usabilidade de Interfaces Humano Computador

CINAHPA | 2017 - Congresso Internacional de Ambientes Hipermídia para Aprendizagem. produtivos, evidente nas indústrias de grande porte, com alto grau de competitividade e número expressivo de funcionários, empresas de pequeno porte ainda são negligenciadas em muitos aspectos. Junto a isso Da Silva, Silvério e Porto (200-, p.01) mencionam que as ambiências físicas devem ser consideradas ainda na etapa de concepção do projeto, a fim de que posteriormente deficiências projetuais do espaço de trabalho não venham a ocorrer, gerando incômodo para os operários e gasto adicional por parte da indústria, que ao mesmo tempo se depara com problemas relativos à queda de produtividade e acidentes de trabalho. A falta de um layout projetado em empresas do ramo de marcenaria não proporciona segurança e conforto para os trabalhadores.

Frente à relevância da iluminação para as diversas atividades cotidianas e não menos importante, a sua participação na cadeia produtiva industrial, especialmente em processos industriais com necessidade de precisão com maquinários de corte e com a presença de "padrões de cores variados", onde a acuidade visual se faz necessária a avaliação deste tipo de ambiente torna-se primordial.

Em empresas de pequeno porte este estudo é ainda mais relevante por serem locais onde os programas de ergonomia não se encontram em grande difusão. Assim, o conhecimento destes espaços, bem como a avaliação dos índices de iluminação existentes e a possibilidade de eventuais melhorias se faz essencial para o cotidiano de uma empresa.

O objetivo deste artigo é apresentar uma avaliação de iluminação em uma marcenaria apontando o estado atual do objeto estudado, bem como sua contraposição aos índices ideais presentes na legislação e aos padrões ergonômicos em relação à atividade desenvolvida (marcenaria), buscando assim, propor medidas de controle para que venham garantir aos trabalhadores deste ambiente, níveis ergonômicos satisfatórios quanto ao conforto ambiental (iluminação).
Realização:
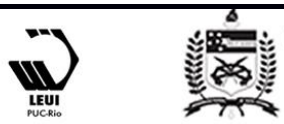


\section{$16^{\circ}$ \\ ERGODESIGN USIHC CINAHPA}

\section{MÉTODO}

Tratando-se de uma pesquisa de abordagem quantitativa buscaram-se dados relevantes ao tema iluminação, sendo esta aplicada à indústria de móveis de pequeno porte (marcenaria) a partir de características presentes no ambiente pesquisado, bem como dados técnicos e científicos para comparação. Foi desenvolvida em duas frentes, a primeira uma revisão bibliográfica, pela qual foram retirados conceituação básica de termos correlatos ao tema e parâmetros para a elaboração do levantamento e futuras comparações com os resultados obtidos. E por segundo a efetivação do levantamento propriamente dito e coleta de dados in loco, com as medições físicas do ambiente, reconhecimento do layout e a disposição do mobiliário e maquinário, captura de imagens para análises posteriores e medições quanto aos níveis de iluminação.

\subsection{Levantamento físico do objeto de estudo}

$\mathrm{O}$ estudo foi realizado em uma marcenaria sediada no município de Fraiburgo/SC, o qual apresenta um processo produtivo de pequeno porte, sendo atendido um cliente/projeto por vez e número reduzido de funcionários, dois colaboradores fixos e um terceiro eventual. Possui uma área de $268 \mathrm{~m}^{2}$ aproximadamente conforme Figura 1, nos quais estão distribuídos setores de produção, estoque de materiais, depósito de ferramentas e estoque de peças prontas. Como ilustra a Figura 2 neste ambiente se encontram os maquinários necessários ao processo produtivo, coladeira de borda (A), uma furadeira múltipla (B), um motoesmeril (C), uma furadeira de bancada (D), uma plaina desempenadeira $(\mathrm{E})$, uma esquadrejadeira $(\mathrm{F})$, uma serra esquadria $(\mathrm{G})$, coletores de pó $(\mathrm{H})$ e um compressor (I), além de ferramentas manuais como alicate, furadeira, parafusadeira e chaves.

Como parte do levantamento também foram elencadas as luminárias existentes no local, bem como o tipo de lâmpadas que compunham o sistema de iluminação. Uma de suas laterais é uma parede cega, onde não há captação de iluminação natural, sendo neste espaço o local de depósito de chapas de MDF e mobiliário já executado. Na outra parede lateral (fachada Oeste) estão dispostas $16^{\circ}$ Ergodesign - Congresso Internacional de Ergonomia e Usabilidade de Interfaces Humano Tecnológica: Produto, Informações Ambientes Construídos e Transporte

$16^{\circ}$ USIHC - Congresso Internacional de Ergonomia e Usabilidade de Interfaces Humano Computador

CINAHPA | 2017 - Congresso Internacional de Ambientes Hipermídia para Aprendizagem.

as aberturas, por onde há entrada de luz natural, são janelas do tipo basculante com vidro incolor fantasia martelado.

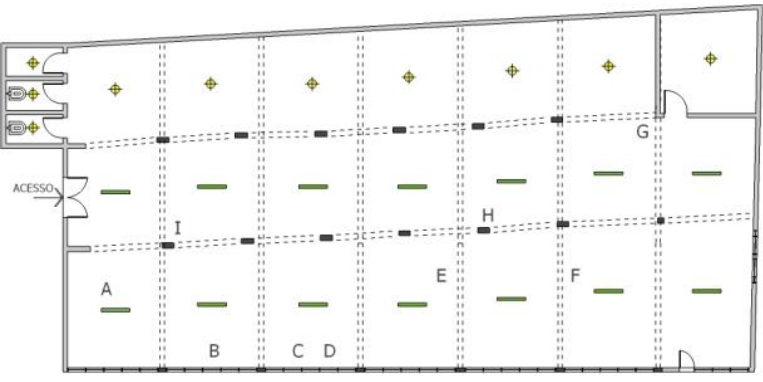

Figura 1 - Planta Baixa do Setor Fabril (marcenaria).

A edificação, como um todo, foi construída com estrutura de concreto e fechamentos em alvenaria. A estrutura de concreto, vigas e pilares, assim como a laje superior, composta por vigotas e tavelas, não apresentam acabamento. As paredes de alvenaria apresentam reboco de cimento e o piso é em concreto alisado elementos estes que podem ser visualizados na Figura2.



Figura 2 - Vista interna do objeto de estudo.

\subsection{Método de levantamento de iluminância e avaliação: Nbr 5382 e Nbr 5413}

O levantamento foi realizado seguindo a metodologia proposta pela NBR 5382 (1985), pois trata da verificação de iluminância de interiores, e adota padrões e procedimentos para que a medição ocorra em áreas retangulares, sendo esta a característica do objeto de estudo. A iluminância é a grandeza fotométrica relacionada à quantidade de luz incidente em determinada área de superfície (GRIGOLETTI, 2008), com a qual é possível realizar medições e avaliações, garantindo
Realização:
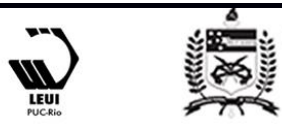


\section{$16^{\circ}$ \\ ERGODESIGN USIHC CINAHPA}

atendimento às necessidades específicas de cada ambiente e atividade.

Para este ambiente em questão, o método de verificação se enquadra no item 4.1 da norma NBR 5382, que se refere a um campo de trabalho retangular, iluminado regularmente por fileiras espaçadas simetricamente em duas ou mais fileiras. Desse modo, seguiram-se as instruções de medição contidas nos seus subitens, elaborando médias aritméticas, e obtendo no fim deste processo a iluminância média dada pela expressão

$$
\frac{R(N-1)(M-1)+Q(N-1)+T(M-1)+P}{N M}
$$

, onde $\mathrm{N}$ refere-se ao número de luminárias por fila e $\mathrm{M}$ ao número de filas.

A iluminância média, proveniente da iluminação geral, é verificada com o uso de uma fotocélula de captação, no caso utilizou-se um luxímetro ICEL LD-500 (Figura3) sobre um plano horizontal sendo que este plano deve estar a uma distância de $80 \mathrm{~cm}$ do piso, para tanto utilizou-se uma estação de trabalho que atendia estes padrões de altura. A medição foi feita atentando para o período de estabilização pré-medição, entre $5 \mathrm{~min}$ e $10 \mathrm{~min}$, bem como para medição efetiva em cada ponto, por períodos de igualmente $10 \mathrm{~min}$.

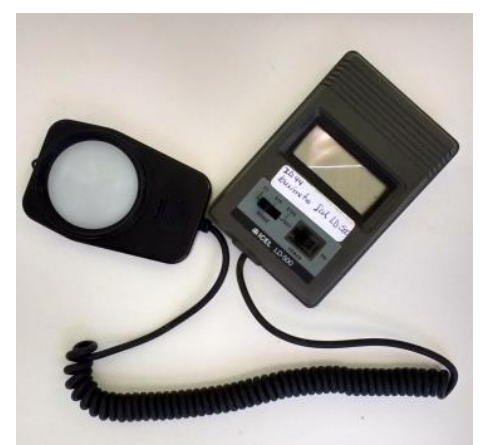

Figura 3 - Luxímetro.

Durante o levantamento todas as lâmpadas, que se encontravam funcionando, foram deixadas ligadas. Além disso, não foi feito nenhum rearranjo nos equipamentos e possíveis anteparos, como mobiliário já produzido, para manter a integridade e realismo quanto às condições existentes no local, sendo este o cenário que a fábrica se encontra diariamente. Deste modo e com a utilização correta dos métodos de verificação compatíveis com a área de estudo, os valores de iluminância média obtidos apresentam um erro máximo de $10 \%$.

Foram consideradas para o estudo, além da aparelhagem utilizada as condições ambientais existentes, no caso dias com céu aberto, parcialmente nublado e nublado. Para a obtenção dos dados necessários para esta análise, foram coletadas informações em três dias distintos, observando a variação de iluminação natural e sua influência sobre os parâmetros de iluminância internos e da iluminação artificial do ambiente. Também se levou em conta o turno de trabalho dos funcionários, que ocorre das 07:30 as 12:00 pela manhã, e a tarde das 13:30 as 18:00.

A medição ocorreu em 18 pontos, segundo a metodologia utilizada (Figura 4). As medidas resultantes foram anotadas junto ao layout com os pontos de referência em todos os seis períodos de levantamento. A partir dos resultados obtidos foram elaborados os cálculos seguindo a metodologia da NBR 5382. Para tanto efetuou-se a média aritmética das oito medições referentes a uma área típica central $(\mathrm{R}=$ $\mathrm{r} 1+\mathrm{r} 2+\mathrm{r} 3+\mathrm{r} 4+\mathrm{r} 5+\mathrm{r} 6+\mathrm{r} 7+\mathrm{r} 8 / 8)$; uma segunda média aritmética (Q) de quatro leituras (q1, q2, q3 e q4) de duas meias áreas típicas, em cada lado do recinto; seguida pela média $(\mathrm{T})$ das leituras nos quatro locais t $1, \mathrm{t} 2$, t3 e t4; e por fim a média aritmética $(\mathrm{P})$ das leituras nos dois lugares p1 e p2 em dois cantos típicos.

A iluminância média na área, a partir das médias aritméticas acima apresentadas, é aferida pela equação $\mathrm{Im}=\mathrm{R}(\mathrm{N}-1)(\mathrm{M}-1)+\mathrm{Q}(\mathrm{N}-1)+\mathrm{T}(\mathrm{M}-$ 1)+P/NM, onde $\mathrm{N}$ é o número de luminárias por fila, 3 no caso, e $\mathrm{M}$ o número de filas, que para o ambiente em questão este número é 7 . Tanto os valores das medições quanto o resultado da iluminância média é dado pela unidade de medida lux (lx). Com este resultado foi possível verificar se os índices encontrados no ambiente estão de acordo com os índices que a legislação, no caso a NBR 5413 (1992, p.11), indica como os ideais para este tipo de atividade, marcenaria.
Realização:
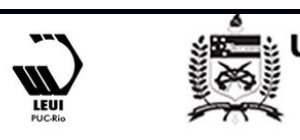


\section{$16^{\circ}$ \\ ERGODESIGN USIHC CINAHPA}

$16^{\circ}$ Ergodesign - Congresso Internacional de Ergonomia e Usabilidade de Interfaces Humano Tecnológica: Produto, Informações Ambientes Construídos e Transporte

$16^{\circ}$ USIHC - Congresso Internacional de Ergonomia e Usabilidade de Interfaces Humano Computador

CINAHPA | 2017 - Congresso Internacional de Ambientes Hipermídia para Aprendizagem.



Figura 4 - Layout dos pontos para as medições de iluminância segundo NBR 5382.

Os índices ideais citados acima adotados pela NBR 5413, para o serviço em questão o de marcenaria, encontram-se em seu item 5.3.59. Neste os índices de referência são associados a três grupos de atividades que são desenvolvidas neste tipo de estabelecimento, serragem, aparelhamento e trabalho grosseiro com índices 150 - 200 - 300lx; para dimensionamento, plainagem, lixamento grosso, aparelhamento semipreciso, colagem, folheamento e montagem a iluminância ficam entre 200 - 300 - 5001x; e quanto ao aparelhamento de precisão, lixamento fino e acabamento os valores estão entre 300 - 500 - 750lx. Todas as atividades elencadas pela NBR 5413 apresentam três iluminâncias, de um modo geral deve ser considerado o valor do intermediário.

Os demais valores são utilizados de acordo com alguns parâmetros específicos como em tarefa que apresente refletâncias e contrastes bastante baixos; onde erros são de difícil correção; trabalhos visuais críticos; necessidade de alta produtividade ou precisão; capacidade visual do observador abaixo da média, nestes casos utiliza-se o índice de maior valor. Já para refletâncias ou contrastes relativamente altos; velocidade e/ou precisão sem importância; e tarefas executadas ocasionalmente, o menor valor é utilizado.

\section{Análise de resultados}

De posse dos dados coletados e feita à análise da iluminação do ambiente da marcenaria, foi possível vislumbrar um panorama de como se encontra a situação do local, quais os elementos que mais tem influência, tanto positiva quanto negativamente e poder assim apresentar recomendações para a adequação do ambiente, baseado em pesquisa a literatura relacionada ao assunto, elencando possibilidades de melhorias a serem aplicadas, para então, atingir os níveis e melhorar a qualidade ambiental e laboral dos usuários do local.

\subsection{Diagnóstico do ambiente de trabalho}

Durante o levantamento e medições, através da observação do ambiente de estudo antes mesmo dos cálculos serem efetuados, já foi possível constatar alguns elementos que além dos índices médios de iluminância também tem grande relevância e em muito refletem nos resultados numéricos.

Em primeiro a diversidade quanto à tipologia de luminárias e lâmpadas, sendo que estas últimas também apresentam variação de potência, o que dificulta o controle da iluminância geral. A falta de manutenção é outro elemento constatado, pelo número de lâmpadas queimadas ou faltantes. Observou-se a não padronização deste sistema havendo cinco tipos de luminárias, em geral luminárias tipo calha com padronagem diversa e ainda luminária tipo soquete. A tipologia das lâmpadas também é diversa variando entre tubulares $(2 \times 40 \mathrm{~W})$, incandescentes e fluorescentes compactas (Figura5).

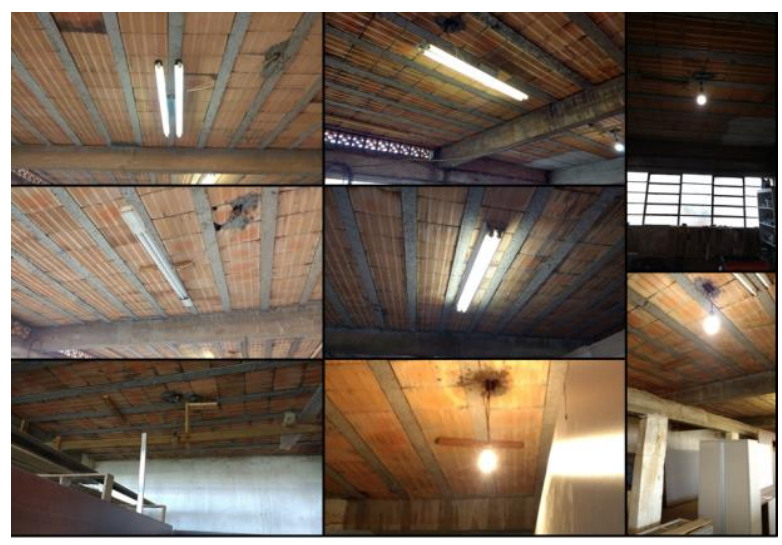

Figura 5 - Exemplares de iluminação artificial.

Foi constatada a não existência de lâmpadas em alguns pontos de ligação, bem como o fato de algumas destas estarem queimadas. Além disso, 


\section{$16^{\circ}$ \\ ERGODESIGN USIHC CINAHPA}

todos os pontos encontram-se fixados junto ao teto, tendo em média uma distância de 2,12m da superfície dos postos de trabalho, já que o pédireito é de 2,92m e a média das bancadas de trabalho é de $80 \mathrm{~cm}$. Outra observação é quanto à distribuição do sistema, feita nas áreas entre as intersecções das vigas junto ao forro, e por se tratar de uma iluminação geral nem todas as estações de trabalho e maquinário possuem sua superfície recebendo iluminação necessária.

Finalmente ao efetuar a análise dos resultados obtidos pelos cálculos dos dados das medições foi verificada uma variação de índices médios de iluminância. Essa variação pode ser associada às condições climáticas e aos períodos nos quais as medições ocorreram. No período matutino obtevese 936lux e 948 lux na condição de céu limpo, e 655lux para céu nublado. Já no período vespertino para céu limpo a iluminação média ficou em 2755lux, para céu com poucas nuvens 2480lux, e por fim para céu nublado 1584lux.

A partir disso é possível constatar que a iluminação média existente no objeto de estudo atende a legislação quanto aos índices padrões. No entanto, por elementos visuais apresentados anteriormente que podem acarretar em efeitos visuais prejudiciais, bem como a grande variação dos valores das medições em diferentes pontos da área levantada, acredita-se que são necessárias certas adequações para melhorar de forma efetiva o desempenho da iluminação do ambiente, como também garantir um ambiente que atenda os padrões ergonômicos como um todo.

\subsection{Sugestões para adequação do ambiente de trabalho}

Constatou-se o atendimento aos índices previstos em norma para a iluminância média do ambiente. Em todos os seis cenários de medições propostos os valores levantados ficaram acima dos valores citados na NBR 5413. No entanto, estes mesmos valores levaram a constatação da grande amplitude entre os pontos medidos se analisados separadamente. $16^{\circ}$ Ergodesign - Congresso Internacional de Ergonomia e Usabilidade de Interfaces Humano Tecnológica: Produto, Informações Ambientes Construídos e Transporte

$16^{\circ}$ USIHC - Congresso Internacional de Ergonomia e Usabilidade de Interfaces Humano Computador

CINAHPA | 2017 - Congresso Internacional de Ambientes Hipermídia para Aprendizagem.
Observou-se nos pontos junto às aberturas os valores mais altos de iluminância, o que mostra a influência direta da iluminação natural. Em muitos aspectos ela é de grande valia, tanto por questões econômicas, pois diminui a necessidade da atuação direta do sistema de iluminação artificial em todos os períodos, como também tem efeitos psicológicos sobre o ser humano, de modo a trazer conforto para os usuários do ambiente estudado.

Porém, em outros aspectos, como alguns analisados por esta pesquisa, quando a iluminação natural não apresenta um controle adequado de acordo com o ambiente, ocasiona alguns distúrbios, no caso visuais.

Por se tratar de uma edificação que não foi projetada para o uso específico de uma marcenaria, propõem-se ajustes de controle da iluminação natural que não interfiram na estrutura do ambiente. Para tanto, sugere-se a colocação de venezianas industriais, com estrutura autônoma, podendo ser afixada da face externa das aberturas, sendo estas projetadas com a angulação de acordo com a incidência da radiação solar para a orientação da fachada em questão - Oeste. Outro elemento de menor impacto seriam persianas instaladas no interior da edificação junto às janelas, estas acionadas pelos próprios funcionários em horários onde a incidência solar for maior, esse sistema requer uma manutenção frequente devido à poeira existente no local. Estes mecanismos seriam responsáveis por evitar o ofuscamento direto e indireto ocasionado pela radiação solar, além de possibilitar índices de iluminância mais homogêneos na área de trabalho.

Quanto ao sistema de iluminação artificial propriamente dito alguns aspectos devem ser observados. Sugere-se a utilização de luminárias pendentes que tragam iluminação direta sobre os postos de trabalho. Com a escolha do tipo de luminária feita entende-se que deve haver uma padronização do sistema, diferentemente do que se encontra hoje, para deste modo poder ser feito um controle efetivo dos níveis de iluminação, além de favorecer a própria manutenção, com um único tipo de luminária e lâmpada. Ainda com relação à manutenção sugere-se a aplicação de um procedimento com prazos definidos para que a 


\section{$16^{\circ}$ \\ ERGODESIGN USIHC CINAHPA}

manutenção do sistema seja periódica, tanto de forma preventiva, com o acompanhamento do desempenho do sistema e limpeza, quanto reparatória, com a troca de luminárias, reatores ou lâmpadas.

Outro fator relevante é o posicionamento das novas luminárias de modo a evitar ofuscamento e sombras, para tanto um estudo de layout se faz necessário de acordo com o posicionamento entre ponto de inserção da luminária e os postos de trabalho, tem-se como recomendação que as fontes de luz estejam locadas nas laterais das estações de trabalho, para que haja um direcionamento lateral dos raios luminosos. Desse modo, um rearranjo do layout como um todo da fábrica seria o ideal, pois deverá haver uma realocação do maquinário para melhor orientá-lo, bem como o número maior de pontos de iluminação (Figura6).

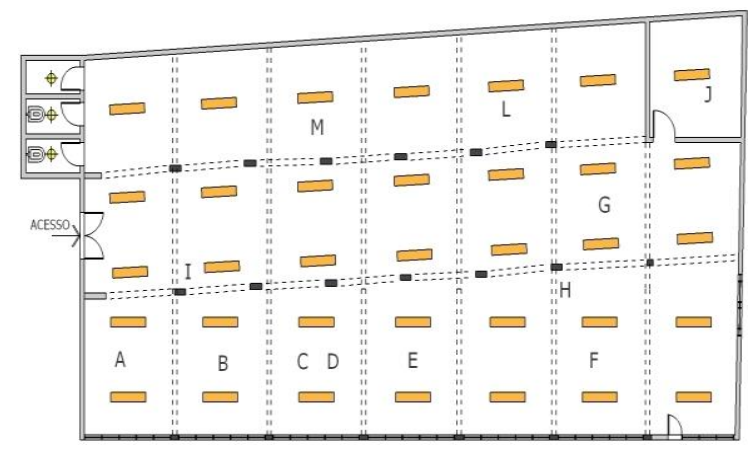

Figura 6 - Novo layout para as luminárias.

E por fim a escolha da luminária em si seguindo padrões adequados, e dimensionados juntamente ao tipo de lâmpada, considerando as dimensões do ambiente e as quantidades necessárias, para atender os níveis mínimos de iluminância recomendados. Fez-se o uso do software Softlux 2.2 (ITAIM, 2017), com o qual é possível simular a iluminância no ambiente de estudo, através de padrões de luminárias e lâmpadas presentes em seu banco de dados, associado ao nível de iluminância adequado para a atividade, no caso 500lux de acordo com a NBR 5413. Foi possível também considerar fatores de restrição quanto à distribuição das luminárias no ambiente. Foram feitas algumas tentativas, até chegar ao cenário, que ao agregar todos os fatores mencionados, se $16^{\circ}$ Ergodesign - Congresso Internacional de Ergonomia e Usabilidade de Interfaces Humano Tecnológica: Produto, Informações Ambientes Construídos e Transporte

$16^{\circ}$ USIHC - Congresso Internacional de Ergonomia e Usabilidade de Interfaces Humano Computador

CINAHPA | 2017 - Congresso Internacional de Ambientes Hipermídia para Aprendizagem.

mostrou como o mais favorável e é apresentado na sequência (Figura7 e Figura8).

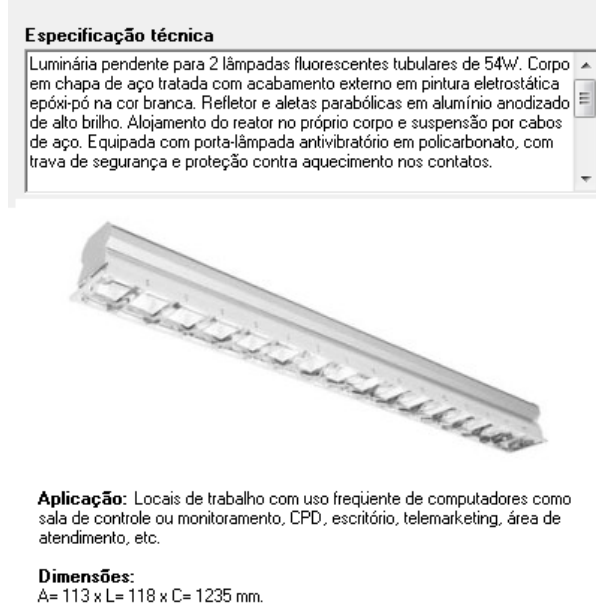

Figura 7 - Modelo e aplicação da nova luminária.

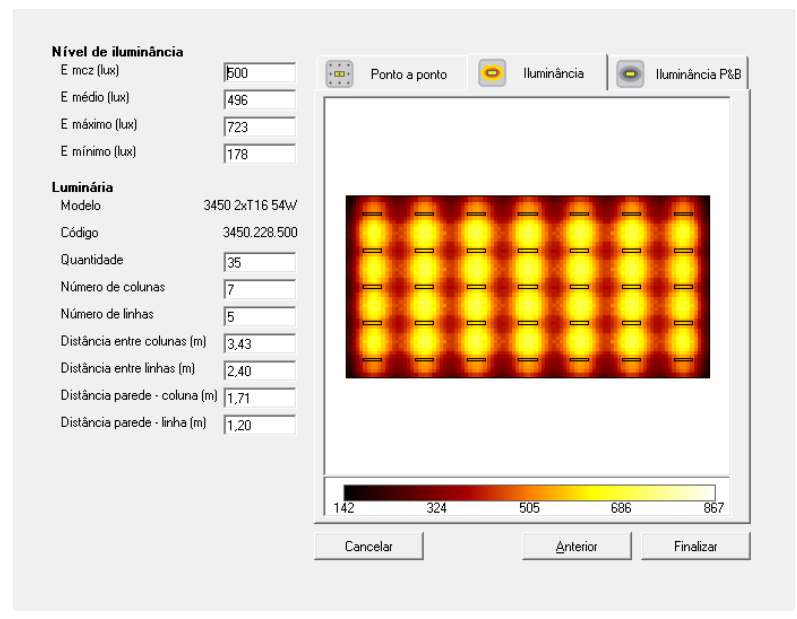

Figura 8 - Parâmetros fotométricos.

\section{Conclusões}

Os estudos na área de iluminação servem tanto para o surgimento de novas tecnologias voltadas a eficiência energética quanto para avaliações de como os espaços que utilizamos diariamente estão dispostos frente a padrões e legislações, sendo este último o foco deste trabalho, que, além disso, demonstrou a importância da iluminação e seus diversos fatores, os quais interferem em vários aspectos da vida humana, em especial o ambiente laboral. Através do levantamento e análises
Realização:
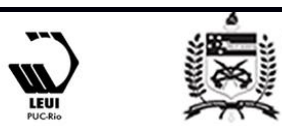


\section{$16^{\circ}$ \\ ERGODESIGN USIHC CINAHPA}

realizadas foi possível observar características próprias do objeto de estudo envolvendo tanto a iluminação artificial quanto a natural, tendo como finalidade a constatação da situação encontrada seguida da elaboração de diretrizes para a adequação do espaço estudado.

Com essa pesquisa buscou-se contribuir para elucidação de assuntos relacionados à iluminação desde seu conceito mais abrangente até sua aplicação e influência prática em ambientes de trabalho, que acabam de muitas maneiras sendo negligenciados. O que levou a constatação de que as dificuldades existentes são muitas, já que em áreas de trabalho como empresas de pequeno porte os espaços que irão receber as atividades, muitas vezes, não são projetados para este fim, trazendo elementos físicos que se sobrepõe aos padrões mínimos necessários a um espaço ergonomicamente adequado. No entanto, também foi possível abordar alguns aspectos do que pode ser feito quando não se tem toda a liberdade para as adequações, buscando do mesmo modo que as atividades sejam realizadas em ambientes, que além de atender a legislação buscam o conforto e a ergonomia para os colaboradores que fazem uso do espaço.

Essa pesquisa pode orientar, ainda, novos trabalhos, dispostos a discutir os resultados frente à eficiência energética, abrangendo as questões econômicas. Sugere-se também, para trabalhos posteriores, um estudo que envolva a aplicação prática dos procedimentos desenvolvidos na concepção de projetos de iluminação, para assim poder ser feita uma reavaliação do ambiente, e obter-se os resultados a partir do projeto de readequação proposto, além disso, se faz de grande valia um levantamento junto aos colaboradores agregando ao conhecimento técnico a percepção do usuário do local, podendo assim abordar outras dificuldades que apenas os dados presentes na legislação não são suficientes para tornar o ambiente um todo confortável, usual e ergonômico.

\section{BIBLIOGRAFIA}

ABNT. ASSOCIAÇÃO BRASILEIRA DE $16^{\circ}$ Ergodesign - Congresso Internacional de Ergonomia e Usabilidade de Interfaces Humano Tecnológica: Produto, Informações Ambientes Construídos e Transporte

$16^{\circ}$ USIHC - Congresso Internacional de Ergonomia e Usabilidade de Interfaces Humano Computador

CINAHPA | 2017 - Congresso Internacional de Ambientes Hipermídia para Aprendizagem.

NORMAS TÉCNICAS. NBR 5382. Verificação de iluminância de interiores, abr. 1985.

. ASSOCIAÇÃO BRASILEIRA DE NORMAS TÉCNICAS. NBR 5413. Iluminância de interiores, abr. 1992.

DA SILVA, Ana Paula Ferreira; SILVÉRIO, Cátia Siciliano; PORTO, Maria Maia. O projeto de iluminação na análise ergonômica do trabalho. [200-]. Disponível em:

<http://www.iar.unicamp.br/lab/luz/ld/Arquitetural/ interiores/ilumina\%E7\%E3o\%20industrial/o_proje to_de_iluminacao_na_analise_ergonomica_do_tra balho.pdf>. Acesso em: 06 jun. 2016.

\section{GRIGOLETTI, Giane. Apostila da Disciplina}

DAU2062 : Conforto Ambiental II. 2008. Curso de Graduação em Arquitetura e Urbanismo. UFSM,

Universidade Federal de Santa Maria.

IIDA, Itiro. Ergonomia: Projeto e Produção. 2. ed. São Paulo: Edgard Blücher, 2005.

ITAIM, Iluminação. Softlux: Software de cálculo luminotécnico. 2017. Disponível em: < http://www.itaimiluminacao.com.br/servicos/down loads>. Acesso em: 19 fev. 2017.

\section{NEUFERT, Ernst. Arte de Projetar em}

Arquitetura. $18^{a}$ ed. São Paulo: Ed. Gustavo Gili, 2013.

PEREIRA, Fernando Oscar Ruttkay; SOUZA, Marcos Barros de. Apostila da disciplina de conforto ambiental: iluminação. Florianópolis, 2000. 51 f. Disponível em:

<http://joinville.ifsc.edu.br/ luis.nodari/Luminot\% C3\%A9cnica/Luminot\%C3\%A9cnica\%20UFSC.p df $>$. Acesso em: 06 jun.

\section{Agradecimentos}

Os autores agradecem a Secretaria de PósGraduação da UNIARP e ao Departamento de Laboratórios de Engenharia da UNIARP pelos recursos aplicados no suporte do projeto. 